\title{
Empirical investigation of treatment process of outlet waste water from petroleum industries
}

\begin{abstract}
Nowadays, lake of potable water, development of industries and population growth, extend desalination units. About $72 \%$ of the feed is drained into the sea as concentrated brine wastewater. This large amount of concentrated brine wastewater threatens sea ecosystem as thermal shocking and high salinity. The pretreatment of effluent stream from petroleum refinery is a logical solution to decrease damages which threaten the sea ecosystems. To reach the goal of Zero Discharge Process (ZDP) some experiments were conducted to decrease the total hardness of effluent stream from this desalination unit. So, the determination of the effects of some parameters is considered for decreasing of total hardness in this research. The experiments were conducted for three mineral coagulants by using each coagulant, separately also by coupled coagulants.
\end{abstract}

Volume 2 Issue 5 - 2017

\author{
Babak Dorostkar,' Farshad Farahbod ${ }^{2}$ \\ 'Department of Chemical Engineering, Islamic Azad University, \\ Iran \\ ${ }^{2}$ Department of Chemical Engineering, Islamic Azad University, \\ Iran
}

Correspondence: Farshad Farahbod, Department of Chemical Engineering, Firoozabad Branch, Islamic Azad University, Firoozabad, Iran, Email mf_fche@iauf.ac.ir

Received: October 18,2016 | Published: March 30, 2017

Keywords: treatment process, flocculation, sedimentation, water, calcium hardness, magnesium hardness

Abbreviations: ZDP, zero discharge process; $\mathrm{ZnO}$, zinc oxide; $\mathrm{PbO}$, lead II oxide; $\mathrm{TiO}_{2}$, titanium dioxide

\section{Introduction}

Published researches about the pretreatment of exit wastewater from desalination units are rare. Nowadays, lake of potable water, development of industries and population growth, extend desalination units. Although desalination units have been grown up, but exit brine stream is usually drained into the sea ecosystem. ${ }^{1-4}$ Moreover, annually a large quantity of concentrated brine is discharged into the sea. ${ }^{5,6}$ By treatment of this saline wastewater, it is possible to eliminate the hazardous effects of salinity on sea ecosystem. Additionally two valuable matters, salt and sweet water can be produced. Total hardness and turbidity of wastewater must be reduced during pretreatment process of wastewater to produce Sodium Chloride salt. ${ }^{7,8}$ Coagulants are the matters used to decrease total hardness of wastewater. The pretreatment process includes 3 steps: coagulation, flocculation and sedimentation. Improving the efficiency of pretreatment process depends on water specifications and also the operating parameters. ${ }^{9-11}$ The optimum mixing rate of first pretreatment reactor, type of coagulant, ratio of sodium carbonate to coagulant and sodium hydroxide to coagulant are some of the important factors in operating conditions. Polyelectrolytes or mixture of coagulants can be used to improve the efficiency of total hardness removal. ${ }^{8,12}$ In this research various binary mixtures of three mineral coagulants were investigated quantitatively and qualitatively. The optimum amounts of Sodium Carbonate to coagulant and Sodium Hydroxide to coagulant were studied for each coagulant individually. This shows that the best ratio for Sodium Carbonate to coagulant is three and for Sodium Hydroxide to coagulant is four.

\section{Materials and methods}

\section{Materials}

The experiments are managed for the wastewater of petroleum refinery. Three commercial mineral nano coagulants, zinc oxide $(\mathrm{ZnO})$, lead II oxide $(\mathrm{PbO})$ and titanium dioxide $\left(\mathrm{TiO}_{2}\right)$ are used in the pretreatment process. Moreover in softening process Sodium Carbonate and Sodium Hydroxide must be added to the wastewater. The previous researches in this field are focused on finding the optimum ratio of Sodium Carbonate to coagulant and also Sodium Hydroxide to coagulant and these ratios are used in this work too. These proper values are 3 and 4 respectively.

\section{Experimental apparatus}

Experiments are held in two pretreatment reactors. The capacity of each reactor is 8 liter and each of them equipped by a mixer. The speed of the mixers can be changed by a "control box". Figure 1 shows the pre-treatment set up. 27 types of binary mixtures of coagulants are examined by three mentioned speeds. Total hardness removal reveals the efficiency of softening pretreatment process. The initial total hardness of wastewater is about $50696.3 \mathrm{ppm}$ as $\left(\mathrm{CaCo}_{3}\right)$. The EC of the waste water is about 29543 micro mho per centimeter and with different $\mathrm{pH}$ values. The salinity of feed stream which is entrance to the first pretreatment reactor is about 7 percent. The results show the electrical conductivity, salinity and total hardness vanished, severely in this paper. In addition, the results show the turbidity amount of treated water is decreased in this study.

\section{Results and discussion}

The speed of mixer in the first pretreatment reactor is one of the major operating parameters which affects the size of coagulants and then as a result the softening efficiency. The total hardness removal reveals the efficiency of softening pretreatment process. Figure 1 shows the trend of total hardness removal. This illustrates that the speed of 90rpm in coagulation step increases the total hardness efficiently and also the mixture contains $\mathrm{TiO}_{2}$ and $\mathrm{ZnO}$ has enough capacity to remove total hardness from 50696.3 to about $299 \mathrm{ppm}$ as $\mathrm{CaCo}_{3}$. However if this ratio increases to $8 / 2$ or $9 / 1$ the total harness decreases just about $1.5 \%$, so this is concluded that mixture contains $700 \mathrm{cc}$ of $\mathrm{TiO}_{2}$ to $300 \mathrm{cc}$ of $\mathrm{ZnO}$ is beneficial economically. One of the important aspects on coagulation process is $\mathrm{pH}$ of wastewater. Also the $\mathrm{pH}$ value of clarified water is important in potable water. The total hardness can state the turbidity and electrical conductivity, also. All of 
the obtained results which are shown in the Figures 1A-1I state the treatment is efficient. Experimental results show the ratio for $\mathrm{TiO}_{2} /$

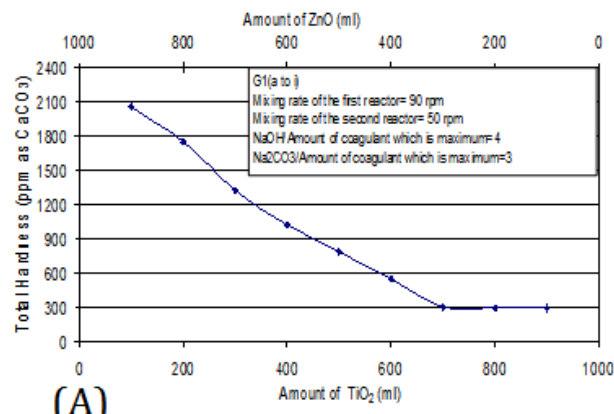

(A)
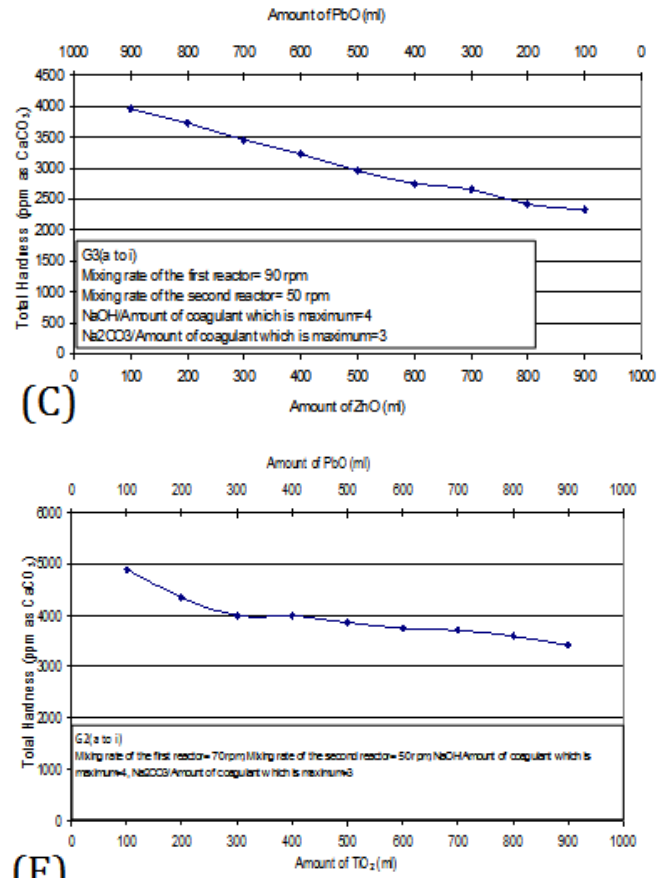

(E)

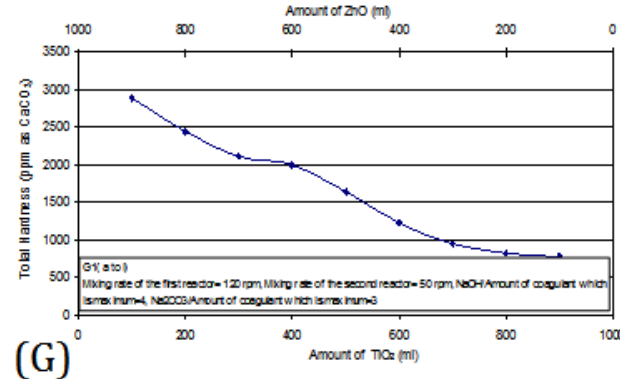

$\mathrm{PbO}$ and also for $\mathrm{TiO}_{2} / \mathrm{ZnO}$ is $3 / 1.5$. So, by increasing the amount of $\mathrm{TiO}_{2}$ in the mixture the value of total hardness decreases.

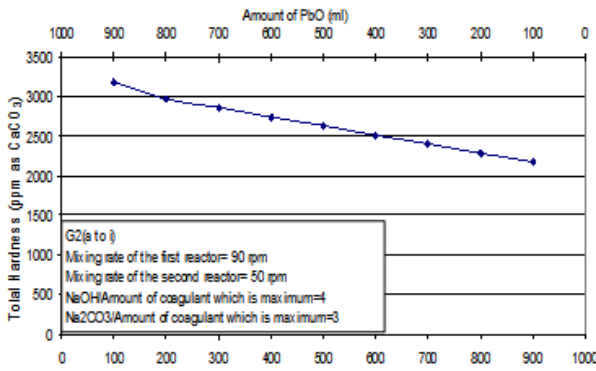

(B) Amosit d $T T_{2}$; (m)

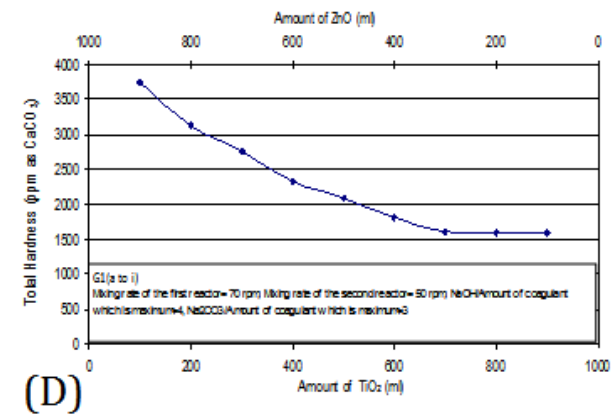

Amount of PbO (ml)

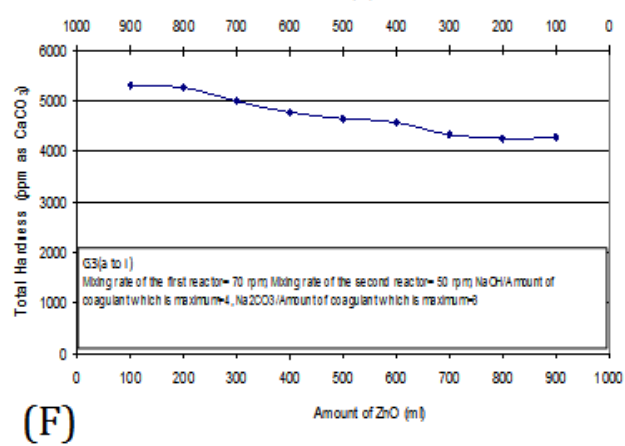

(F)

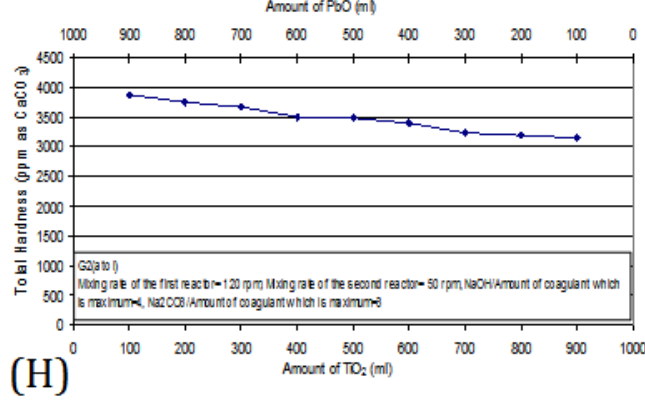

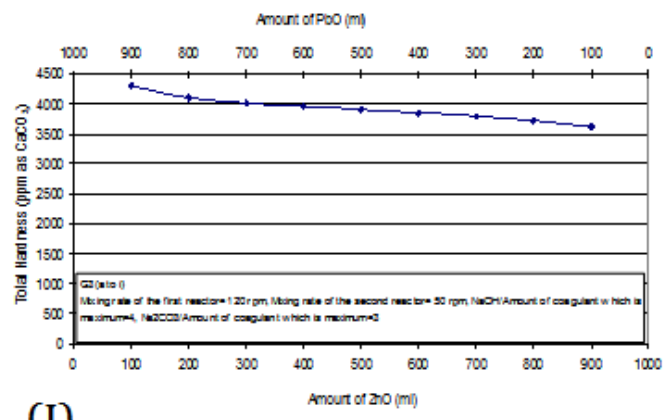

(I)

Figure I variation of total hardness versus amounts of binary mineral coagulant mixtures for different mixing speed.

Citation: Dorostkar B, Farahbod F. Empirical investigation of treatment process of outlet waste water from petroleum industries.J Appl Biotechnol Bioeng. 2017;2(5): 193-195. DOI: 10.15406/jabb.2017.02.00045 


\section{Conclusion}

This work focuses on the finding the major aspects for removing the total hardness of wastewater by different binary mixtures of mineral nano coagulants. The used wastewater is the effluent stream of petroleum refinery. The results reveal that the speed of 90rpm in coagulation step decreases the total hardness efficiently and a mixture containing $\mathrm{TiO}_{2}$ and $\mathrm{ZnO}$ has higher capacity to remove total hardness comparing with the other coupled mixtures. The experiments show that another effective factor on coagulation step is the high ratio of number of anions to the number of cations of coagulant. This ratio for $\mathrm{TiO}_{2} / \mathrm{PbO}$ and also for $\mathrm{TiO}_{2} / \mathrm{ZnO}$ is $3 / 1.5$. So, by increasing the amount of $\mathrm{TiO}_{2}$ in the mixture the value of total hardness decreases.

\section{Acknowledgements}

None.

\section{Conflict of interest}

The author declares no conflict of interest.

\section{References}

1. Khiari R, Dhaouadi SD, Aguir C, et al. Experimental evaluation of eco-friendly flocculants prepared from date palm rachis. J Environ Sci (China). 2010;22(10):1539-1543.

2. Gao B, Chu Y, Yue Q, et al. Purification and characterization of Al13 species in coagulant polyaluminum Chloride. J Environ Sci (China). 2009;21(1):18-22.

3. Beltrán PA, Roca JAM, Piá AB, et al. Application of multicriteria decision analysis to jar-test results for chemicals selection in the physical-chemical treatment of textile wastewater. $J$ Hazard Mater. 2009;164(1):288-295.
4. Yana M, Wang D, Ni J, et al. Natural organic matter (NOM) removal in a typical North-China water plant by enhanced coagulation: Targets and techniques. Sep Purif Technol. 2009;68(3):320-327.

5. Wu Q, Hua T, Zhou Q. Treatment and remediation of a wastewater lagoon using microelectrolysis and modified DAT/IAT methods. J Environ Sci (China). 2011;23(3):388-395.

6. Setiawan AA, Yu Zhao, Nayar CV. Economic analysis and environmental considerations of mini-grid hybrid power system with reverse osmosis desalination plant for remote areas. Renewable Energy. 2009;34(2):374-383.

7. Lee S, Maniquiz MC, Kim LH. Characteristics of contaminants in water and sediment of a constructed. wetland treating piggery wastewater effluent. J Environ Sci (China). 2010;22(6):940-945.

8. Wang Y, Zhoua WZ, Gao BY. The effect of total hardness on the coagulation performance of aluminum salts with different Al species. Separation and Purification Technology. 2009;66(3):457-462.

9. Wang W, Hua Li , Wang X, et al. Spatial variations of aluminum species in drinking water supplies in Xi'an studied applying geographic information system. J Environ Sci. 2010;22:519-525.

10. Jangkorn S, Kuhakaew S, Theantanoo S, et al. Evaluation of reusing alum sludge for the coagulation of industrial wastewater containing mixed anionic surfactants. J Environ Sci (China). 2011;23(4):587-594.

11. Al-Jasser A. Saudi wastewater reuse standards for agricultural irrigation: Riyadh treatment plants effluent compliance. King Saudi University-Eng Sci. 2011;23:1-8.

12. Nan J, He W, Song X, Li G. Impact of dynamic distribution of floc particles on flocculation effect. J Environ Sci (China). 2009;21(8):10591065 . 